\title{
Rheological and Mechanical Characterization of Renewable Resource Based High Molecular Weight PLA Nanocomposites
}

\author{
P. J. Jandas, S. Mohanty, and S. K. Nayak \\ Laboratory for Advanced Research in Polymeric Materials (LARPM), Central Institute of Plastics Engineering and Technology (CIPET), \\ Bhubaneswar, Orissa 751024, India \\ Correspondence should be addressed to S. K. Nayak; papers.journal@gmail.com
}

Received 23 March 2013; Revised 25 June 2013; Accepted 9 July 2013

Academic Editor: Cornelia Vasile

Copyright (C) 2013 P. J. Jandas et al. This is an open access article distributed under the Creative Commons Attribution License, which permits unrestricted use, distribution, and reproduction in any medium, provided the original work is properly cited.

The present study discusses structural aspects of nanocomposites and the ability of layered nanosilicates to alter the flow behaviour of poly(lactic acid) (PLA) melts. In addition, dynamic and static mechanical properties of PLA nanocomposites prepared from melt mixing method have been also discussed. A comparative study of nanocomposite properties has been conducted using two different nanoclays, natural montmorillonite modified with alkyl ammonium surfactant (OMMT), and commercially available organosilicate, Cloisite 30B, as reinforcements within the PLA matrix. Since OMMT has undergone better intercalation within the matrix, the corresponding nanocomposite showed superior mechanical and rheological characteristics than its C30B counterpart.

\section{Introduction}

Environmental impact generated by accumulating petroleum based plastic wastes is one of the most pondering topics among the researchers and environmentalists today. In this view, renewable resource based completely biodegradable aliphatic polyesters like poly(lactic acid) (PLA) and poly (hydroxyalkanoates) (PHA), carbohydrate based materials like starch and cellulose are under the scrutiny as apt replacement for petroleum based plastics. But still processability and cost are major drawbacks of these materials to clinch their niche in the market for various specific applications including "disposable materials." Researchers like Ray et al. reported about the improvements in processability and performance characteristics of PLA by reinforcing it with layered nanosilicates [1]. Also, nanocomposites of PHAs, starch, and petroleum based biodegradable materials like poly(butylene adipate-co-terephthalate) (PBAT) and poly(caprolactone) (PCL) with improved processability; mechanical and thermal characteristics also have been reported by various researchers. Among all, PLA is highly crystalline in nature with inherent biodegradability as well as enough life to maintain mechanical properties without rapid hydrolysis. As per the literature, mechanical and thermal properties of PLA show considerable improvement as a function of extent of intercalation/exfoliation of nanoclay layers within the matrix [2-5].

However, the relationship between structural features and rheological characteristics of PLA melts in its nanocomposites still demands detailed analysis through fundamental point of view to better understand the materials processability under a given set of parameters. In this view, the current study discusses the structural aspects of nanocomposites and the ability of layered nanosilicates to alter the flow behaviour of PLA melts. Further characterizations have been conducted through dynamic and static mechanical analysis. Commercially available organosilicate, Cloisite 30B (C30B), has been used as nanoreinforcement in the study. In addition, natural montmorillonite has been modified organically using hexadecyl trimethyl ammonium bromide (HTAB) surfactant and used to prepare nanocomposite with PLA.

\section{Materials}

Poly(lactic acid) (PLA 4042 D) with a number average molecular weight $\left(M_{w}\right)$ of $120,000 \mathrm{~g} / \mathrm{mol}$ was obtained from NatureWorks (USA) and used as base matrix. Melt flow index 
of PLA has been observed in between 4 and $8 \mathrm{~g} / 10 \mathrm{~min}\left(190^{\circ} \mathrm{C}\right.$, $2.19 \mathrm{~kg}$ ). Organically modified nanoclay, Cloisite 30B (C30B), and natural montmorillonite (NaMMT) were procured from Southern Clay Products (USA). Hexadecyl trimethyl ammonium bromide (HTAB) and all other laboratory reagents have been procured from Sigma Aldrich (Germany) and used without any modification.

\section{Methods}

3.1. Surface Modification of Natural Montmorillonite. In order to reduce the hydrophilicity of montmorillonite, cation exchange reaction was conducted using HTAB as follows. $10 \mathrm{~g}$ of montmorillonite was dispersed in $300 \mathrm{~mL}$ of distilled water using a mechanical stirrer under 2000 cycles/minute rpm for 3 hours followed by sonication for 1 hour. The well dispersed montmorillonite in distilled water was further mixed with surfactant (0.1 molar solution in distilled water) and $2 \mathrm{~mL}$ of concentrated $\mathrm{HCl}$. The mixture was mechanically stirred again for 2 hours followed by centrifugation and filtration till the complete removal of bromide group from the filtrate. Residual bromide was detected using $\mathrm{AgNO}_{3}$ test. Further, the organically modified nanoclay (OMMT) was dried at $80^{\circ} \mathrm{C}$ for 12 hours, cryomilled, and sieved.

3.2. Preparation of Nanocomposites. Nanocomposites have been prepared in a corotating twin-screw microcompounder (DSM Xplore 15, the Netherlands) attached with a miniinjection molder. The extruder is equipped with conical twin screw of length $150 \mathrm{~mm}$ with $L / D$ ratio 18 and net capacity of $15 \mathrm{cc}$. Prior to compounding, PLA and nanoclays were predried at $80^{\circ} \mathrm{C}$ in a vacuum oven for $12 \mathrm{hrs}$ and $4 \mathrm{hrs}$, respectively. Subsequently, the nanocomposites have been prepared using the corotating twin-screw miniextruder with various weight ratios of nanoclays. The processing temperature has been kept as 170,175 , and $180^{\circ} \mathrm{C}$ for the three successive zones of the extruder. Screw speed has been maintained at $40 \mathrm{rpm}$ throughout the total mixing time of 4 minutes. The melt has been collected from the extruder in a preheated container and injection moulded according to the various ASTM standards as mentioned in the characterization section. Injection moulding parameters were fixed as mould temperature at $40^{\circ} \mathrm{C}$, melt temperature at $170^{\circ} \mathrm{C}$, injection time at $5 \mathrm{~s}$, and injection pressure at $145 \mathrm{psi}$.

\section{Characterization}

4.1. Mechanical Testing. Tensile measurements of PLA and its nanocomposites were carried out in Universal Testing Machine (Instron, USA). Dumbbell shaped specimens of dimension $165 \times 12.7 \times 3 \mathrm{~mm}$ as per ASTM D 638 have been used for the testing. Gauge length was fixed at $50 \mathrm{~mm}$ with a cross head of $5 \mathrm{~mm} / \mathrm{min}$ for conducting the test. Specimens of dimension $63.5 \times 12.7 \times 3 \mathrm{~mm}$ were used for impact measurements by means of an Impact tester (CEAST, Italy) as per ASTM D 256. The specimens have been notched at angle of $45^{\circ}$ and depth of $2.54 \mathrm{~mm}$ using notch cutter (CEAST, Italy) prior to test.
4.2. WAXD Analysis. Wide Angle X-ray Diffraction (WAXD) analysis was performed for nanocomposites to study the extent of intercalation/exfoliation within the polymer matrix using Shimadzu X-ray diffractometer 7000L, Japan, (graphite monochromator $\mathrm{Cu} \mathrm{K}_{\infty 1}$ radiation with $\lambda=0.15406 \mathrm{~nm}$ ) at a scanning rate of $0.5^{\circ} / \mathrm{min}$ within a range of $1^{\circ}$ to $50^{\circ}$. The basal spacing of the silicate layer $(d)$ was calculated using Bragg's equation, $\lambda=2 d \sin \theta$.

4.3. TEM Analysis. TEM images of blend nanocomposites have been taken in a transmission electron microscope (TEM 140, JEOL, Japan) operated at an accelerated voltage of $100 \mathrm{kV}$. The sample for imaging has been prepared by slicing it to ultrathin size of less than $100 \mathrm{~nm}$ using Cryo Leica EM UC6 instrument (Leica Microsystems, Switzerland) equipped with a diamond knife, and it was viewed without staining.

4.4. Dynamic Mechanical Analysis (DMA). Viscoelastic properties of PLA and its biocomposites were analysed using dynamic mechanical analyzer (DMA, Q800, TA Instruments, USA). Samples of dimension $63.5 \times 12.7 \times 3 \mathrm{~mm}$ were used for testing under a temperature range of 40 to $140^{\circ} \mathrm{C}$ and a fixed frequency of $1 \mathrm{~Hz}$. The DMA results are expressed as storage modulus $\left(E^{\prime}\right)$ corresponding to the elastic response to the deformation and damping factor $(\tan \partial)$ values.

4.5. Rheological Characterization. Rheological behaviour of nanocomposites was investigated using parallel plate rheometer (Mars III, Thermo Fisher Scientific, Germany). To determine melt rheological parameters like storage modulus $\left(G^{\prime}\right)$, loss modulus $\left(G^{\prime \prime}\right)$, and complex viscosity $\left(\eta^{*}\right)$, dynamic frequency sweep experiment was performed within a range of 0.01 to $100 \mathrm{rad} / \mathrm{s}$ using $25 \mathrm{~mm}$ diameter plate. All measurements were performed at $180^{\circ} \mathrm{C}$ and under $1 \%$ strain.

\section{Results and Discussion}

5.1. Mechanical Properties of PLA Nanocomposites. Variation in mechanical properties of PLA and its nanocomposites as a function of clay loading and clay type is enumerated in Table 1. Incorporation of organoclay results consistent increase in tensile modulus with increased amount of filler content within the matrix. The tensile modulus of PLA increased to the tune of $5.43,12.98$, and $17.07 \%$ with 1 , 3 , and $5 \mathrm{wt} \%$ of nanoclay loading in case of PLA/C30B nanocomposites than that of V-PLA. This behavior reveals effective stress transfer from the $\mathrm{C} 30 \mathrm{~B}$ to the matrix as observed in case of other filled systems reported by Ray et al. [6]. Nanocomposites prepared using OMMT nanoclay have showed optimum tensile modulus with $4.08 \%, 17.09 \%$, and $21.69 \%$ increment for 1,3 , and $5 \mathrm{wt} \%$ OMMT loading as compared with V-PLA, which is possibly due to good level of OMMT intercalation/exfoliation and effective interaction between clay layers and matrix polymer. Similarly, PLA/OMMT nanocomposites exhibited an increase in tensile strength of $18.68 \%$ as compared to that of the matrix polymer. This further confirmed that the intercalation/exfoliation expanded clay galleries of 
TABLE 1: Mechanical properties of PLA and PLA nanocomposites.

\begin{tabular}{|c|c|c|c|c|c|}
\hline Sample & $\mathrm{Wt} \%$ of nanoclay & Tensile modulus (MPa) & Tensile strength (MPa) & Elongation at break & Impact strength $(\mathrm{J} / \mathrm{m})$ \\
\hline V-PLA & 0 & $3550 \pm 50$ & $38 \pm 4$ & 2.91 & 24.7 \\
\hline \multirow{3}{*}{ PLA/C30B } & 1 & $3743 \pm 60$ & $29.3 \pm 4$ & $2.1 \pm 1$ & $25.3 \pm 4$ \\
\hline & 3 & $4011 \pm 34$ & $39.8 \pm 7$ & $2.4 \pm 0.3$ & $32.6 \pm 3$ \\
\hline & 5 & $4156 \pm 56$ & $18.3 \pm 4$ & $0.9 \pm 0.6$ & $21.2 \pm 6$ \\
\hline \multirow{3}{*}{ PLA/OMMT } & 1 & $3695 \pm 69$ & $32.3 \pm 6$ & $2.8 \pm 1$ & $27.3 \pm 4$ \\
\hline & 3 & $4157 \pm 23$ & $45.1 \pm 4$ & $2.3 \pm 0.4$ & $37.2 \pm 3$ \\
\hline & 5 & $4320 \pm 92$ & $25.9 \pm 6$ & $1.5 \pm 0.6$ & $18.3 \pm 5$ \\
\hline
\end{tabular}

OMMT as a result of HTAB modification. According to Yoshida and Okamoto, in case of well intercalated/exfoliated PLA nanocomposites, the matrix chains are strained by organoclay platelets due to their large interfacial area and stronger interactions [7]. Additionally, the cooperative macromolecular movement was suppressed by organoclay tethering and gallery confinement [8]. However, in all the cases, beyond $3 \mathrm{wt} \%$ of nanoclay loading, there was a drastic drop in the tensile strength which indicates agglomeration of the clay particles. This may induce microcracks at the interface of the nanocomposites. The elongation at break of V-PLA and its nanocomposites decreased with filler loading which is similar to the behaviour observed in case of all other filled systems.

Impact strength of PLA also showed increment with increased clay loading from 1 to $3 \mathrm{wt} \%$, beyond which there was a decrease in the strength. PLA/C30B with $3 \mathrm{wt} \%$ of clay loading has been showed $31.98 \%$ higher values than that of V-PLA. This further confirms favourable interaction between the dihydroxyl group present in the surfactant of $\mathrm{C} 30 \mathrm{~B}$ and carbonyl groups of PLA at the interface. An optimum increase in impact strength of PLA matrix to the tune of $50.6 \%$ was observed in case of PLA/OMMT nanocomposites due to the better interaction between the silicate layers and PLA macromolecules due to the high level of intercalation/ exfoliation process.

5.2. Comparative Study of Mechanical Modulus PLA Nanocomposites with Theoretical Values. Numerous micromechanical models [9] are available to predict the elastic constants of discontinuous particulate composites. These models generally depend on parameters including particle/matrix stiffness ratio $E_{p} / E_{m}$, particle volume fraction $V_{f}$, particle aspect ratio $1 / d$, elasticity of the composite, and orientation. In the present study, in order to understand the reinforcing effects of organically modified nanosilicates within the PLA matrix, Halpin-Tsai (H-T) and Mori-Tanaka (M-T) micromechanical models were utilized to calculated theoretical tensile modulus values and compared with the experimental results obtained for PLA nanocomposites.

The current study mainly focuses on the prediction of longitudinal stiffness $\left(E_{c}\right)$ of the nanocomposites reinforced with particulate nanofillers. Using $\mathrm{H}-\mathrm{T}$ and $\mathrm{M}-\mathrm{T}$ equations, exact range of aspect ratio and elasticity preserved by the nanoclay within the nanocomposite, respectively, have been calculated.
5.3. Comparative Study of Experimental and Theoretical Mechanical Modulus by H-T Model. Figures 1(a)-1(b) represent the experimentally and theoretically determined mechanical modulus of PLA nanocomposites using $\mathrm{H}-\mathrm{T}$ equation as a function of different aspect ratio of the filler. As a basic assumption from the literature, aspect ratio has been assumed within a range of 10 to 100 [10-12]. Two extreme conditions of highest and lowest predicted values using parallel and series models are also depicted for reference purpose.

In case of PLA/C30B nanocomposite, the experimental value of elastic modulus shows similarities with the theoretically calculated values at lower volume fractions corresponding to an aspect ratio of 100 . But at higher volume fractions of $\mathrm{C} 30 \mathrm{~B}$, the difference between experimental and theoretical values increases further. However, the values observed corresponding to the other aspect ratios do not show much similarities with the experimental values except a cross over point noted at around $E_{c} / E_{m}=1.07$ for the aspect ratio 75. In case of OMMT reinforced nanocomposites, the experimental values show almost an overlaid nature with values obtained from the $\mathrm{H}$-T equation corresponding to an aspect ratio 75 as shown in Figure 1(b). The extent of deviation from the theoretical values is comparably lower in this case as compared with PLA/C30B nanocomposite.

The exact range of average aspect ratio of the nanoclays has been calculated through the study of variation of elastic modulus with aspect ratio under a fixed volume fraction as given in Figures 2(a)-2(b). Here, the volume fraction is kept at 0.015 for both the nanocomposites which was the optimized composition by tensile and impact properties. From the graph average aspect ratio of nanoclays was determined through the $X$ intercepts of the experimentally determined modulus values. As per Figures 2(a) and 2(b), the average aspect ratio of $\mathrm{C} 30 \mathrm{~B}$ and OMMT was observed at around 61 and 79, respectively, corresponding to their experimentally determined nanocomposites moduli of 4011 and $4157 \mathrm{MPa}$.

Even though, the aspect ratio observed from TEM images of the nanocomposites is comparatively better than that of $\mathrm{H}-\mathrm{T}$ equation suggested values for both C30B and OMMT. The values observed at around 90 and 105, respectively, for C30B and OMMT within the PLA matrix and corresponding elastic moduli values of the respective nanocomposites were observed at 4284 and $4412 \mathrm{MPa}$. The values have been determined by the extrapolation of graph towards $Y$ intercepts of the figure. The values are around 6.8 and $6.1 \%$ higher than those of experimental values reported for PLA/C30B and PLA/OMMT, respectively. The observed variation in 


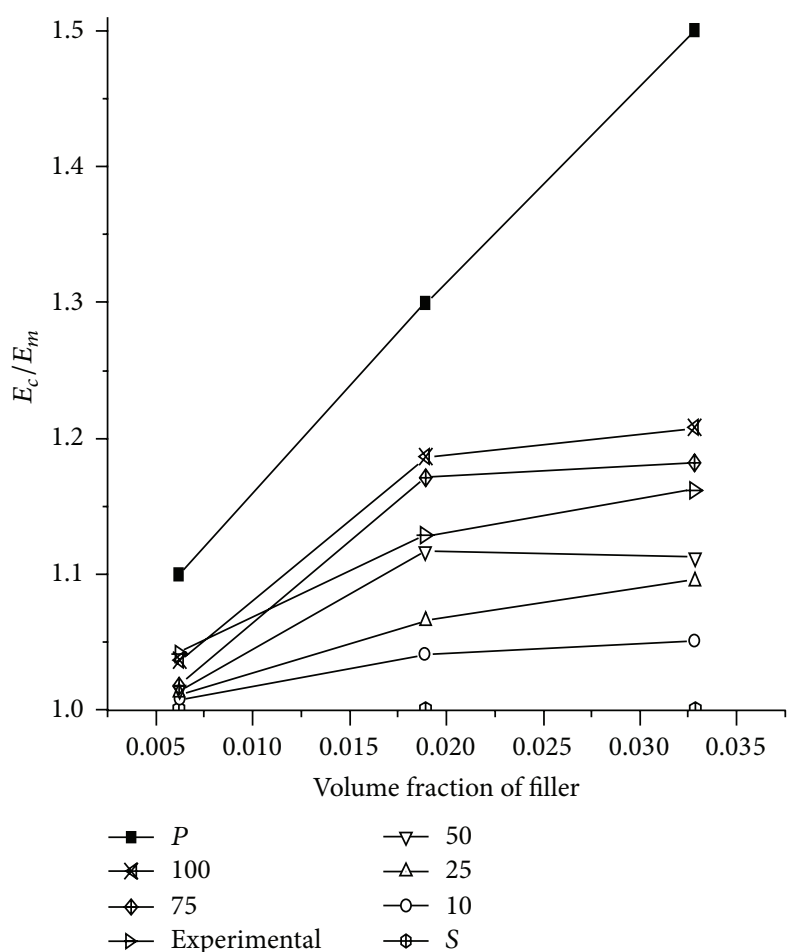

(a)

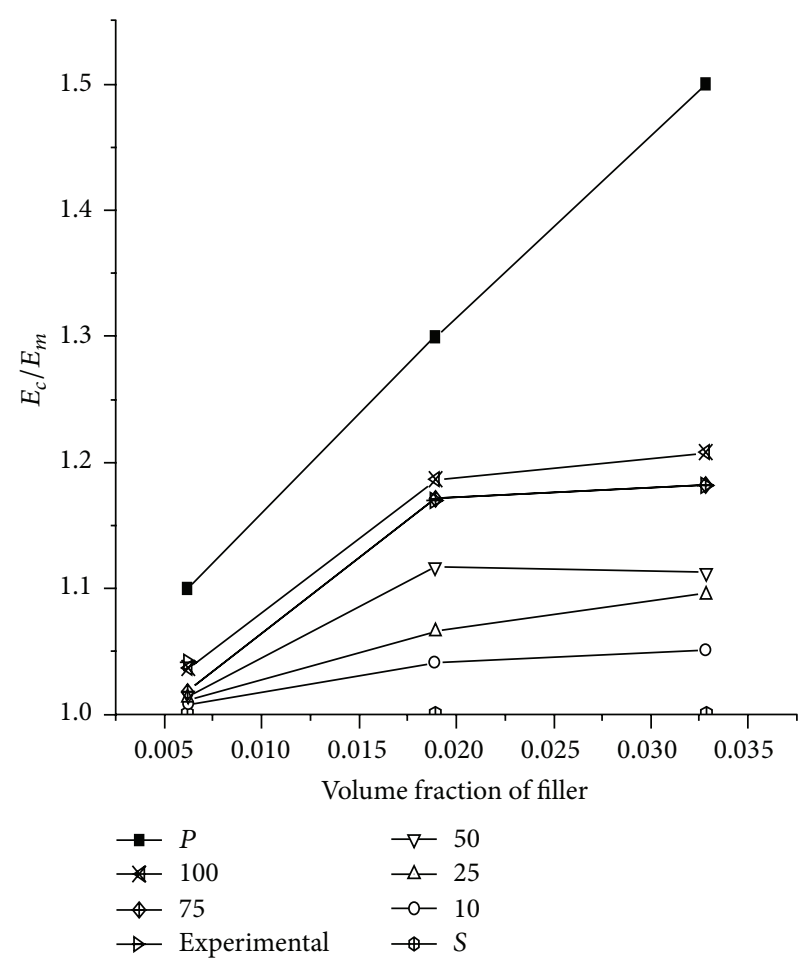

(b)

FIGURE 1: Comparative account of experimental mechanical modulus with H-T equation.

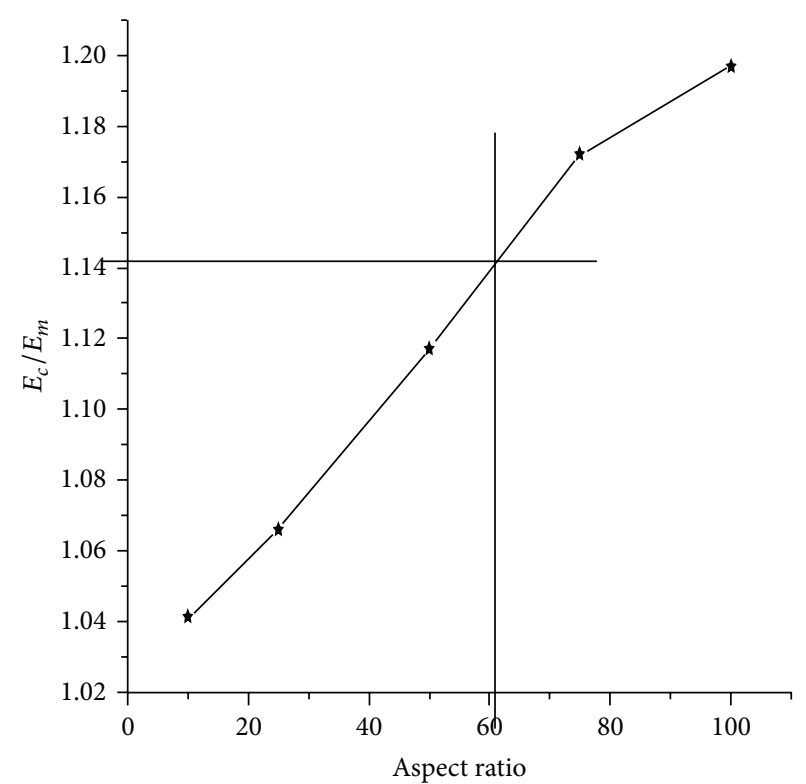

(a)

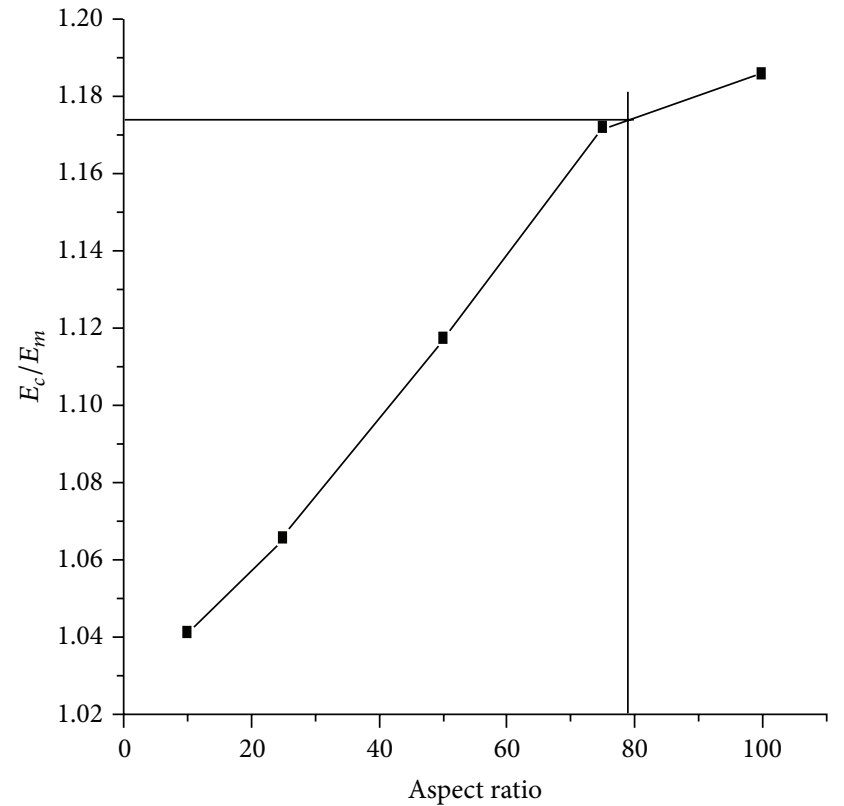

(b)

FIGURE 2: Predicted aspect ratio of nanoclays within PLA by H-T equation.

elastic modulus corresponding to the aspect ratios obtained from H-T model and TEM images can explain through the basic assumptions used for the derivation of $\mathrm{H}-\mathrm{T}$ equation. There are a number of assumptions inherent in the $\mathrm{H}-\mathrm{T}$ equation: (i) properties of both the matrix PLA and the nanoclays within the nanocomposites are identical to those of the pure materials; (ii) matrix and filler lamellae are linear elastic, isotropic, and perfectly bonded; (iii) the filler lamellae are perfectly aligned, asymmetric, and uniform in shape and size. The above assumptions are very much 


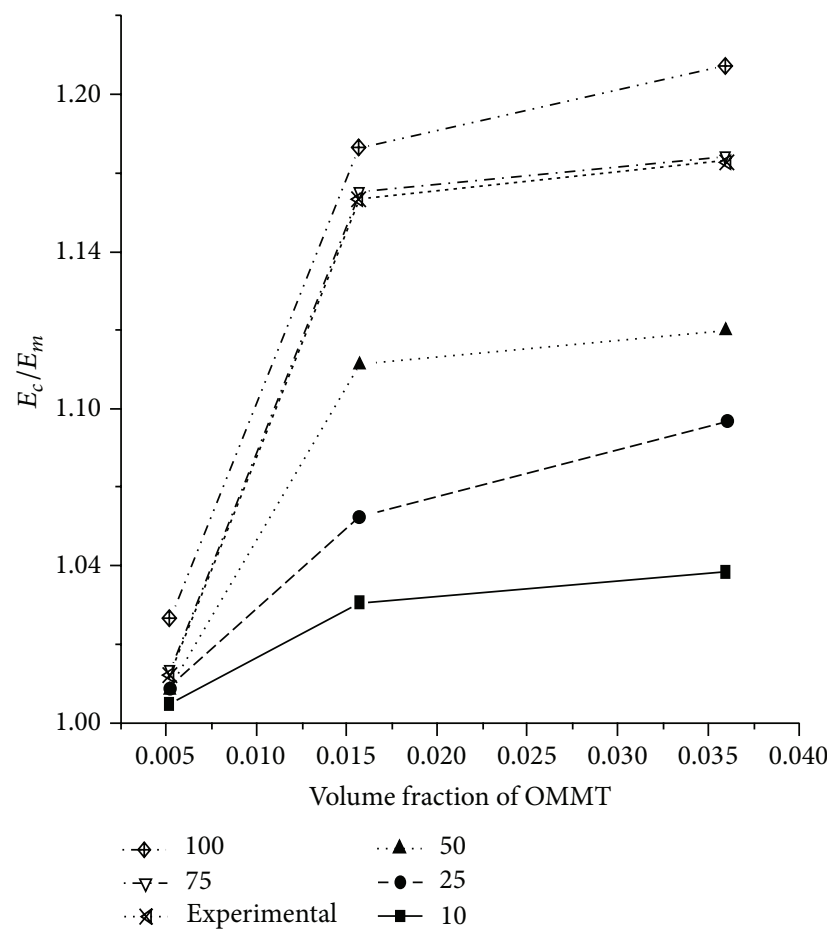

(a)

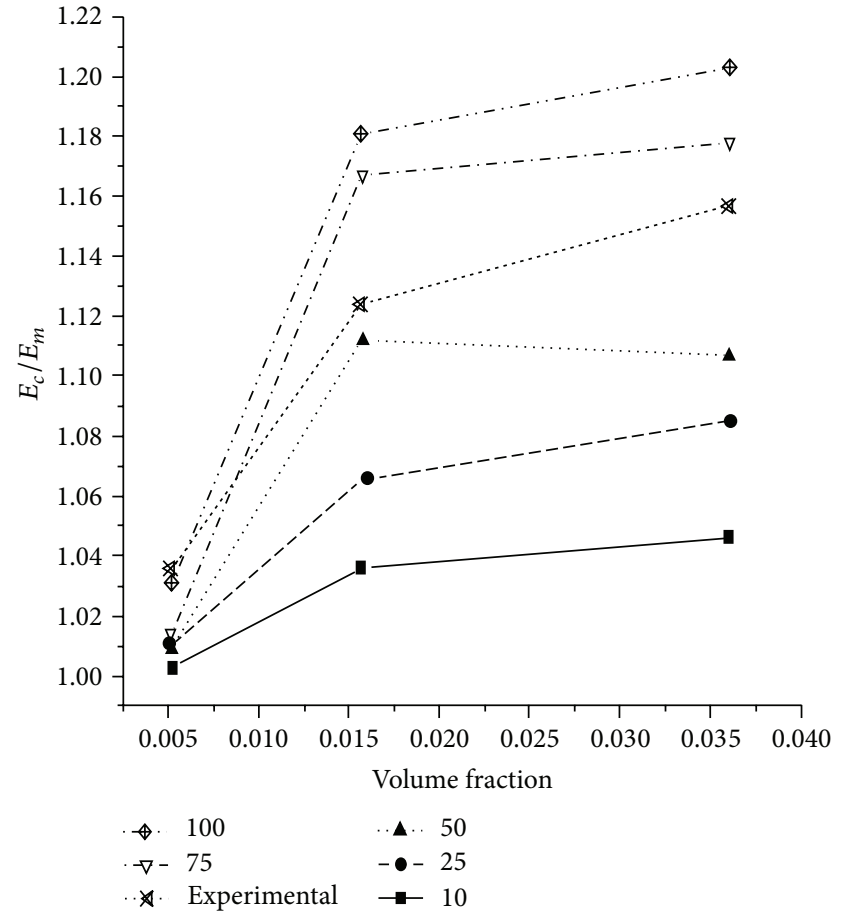

(b)

FIgURE 3: Comparative account of experimental mechanical modulus with M-T equation.

close to an ideal composite behaviour, rather than practical composite nature. These disparities in between ideal and practical situations must create the variation in predicted and real (experimental) behaviour of complex systems such as polymer nanocomposites. Mainly the second array of assumptions like linear elastic and isotropic nature of the filler and a perfect interface between matrix and filler may play vital roles in the present study. The linear elastic and isotropic nature for the filler is a hypothetical condition which is practically unachievable properties as well as the perfect matrix/filler interface also. Even though, there is an enhanced range of interaction in between PLA and layered silicate due to the organic modification of the silicate layer, it is difficult to achieve a perfect distribution of bonds in between the matrix and the intercalated/exfoliated nanoclays. As a result even at higher aspect ratios of silicate layers within the PLA matrix, the resulted nanocomposites cannot show perfect interface which results in lower elastic modulus than the expected or calculated values. However, some deviation from the experimental results has been observed, H-T model is still useful for the prediction of mechanical properties of nanocomposites. Experimental results suggesting that using exact range of aspect ratio of the filler materials, efficiency of $\mathrm{H}-\mathrm{T}$ equation can improve significantly.

5.4. Comparative Study of Experimental and Theoretical Mechanical Modulus by M-T Model. Since the elasticity of nanocomposites affects significantly the predicted values of mechanical properties by H-T model, M-T model is used in the study to estimate the extent of variation in elasticity by the nanocomposite preparation. Figures 3(a), and 3(b) represent the comparative study of elastic modulus of PLA nanocomposites as a function of volume fraction and aspect ratio of the nanoclays. Comparing with the H-T model, both the models show the same expected trends for the prediction of elastic modulus. In the present study, the predicted $E_{c}$ increases almost linearly with increasing $V_{f}$ and aspect ratio of the C30B and OMMT nanoclays. According to Kalaprasad et al. [13], at very low values of $V_{f}\left(V_{f} \ll 1\right)$ both the equations can be linearized in the form,

$$
\frac{E_{c}}{E_{m}}=1+B V_{f},
$$

where $B$ is a positive value (assuming $E_{f} / E_{m}>1$ ), depending on filler aspect ratio and elastic properties of the nanocomposites. Study of variation in $B$ as a function of different volume fractions and aspect ratio will give a vague idea about the dependency of both the factors on the elasticity of the nanocomposites.

Figures 4(a), and 4(b) represent the variation in $B$ with respect to the increase in nanoclay volume fraction and aspect ratio. From the figures, it is evident that the elasticity of the nanocomposites increases with increase in volume fraction of nanoclays upto a limit. The observation is well supported by the viscoelastic study conducted in the DMA section where the storage modulus value of the nanocomposites shows considerably higher than that of V-PLA. The curve was showed an optimum value of elasticity, and further it was reduced with increasing volume fraction. Similarly, calculated elasticity also increased with increasing aspect 


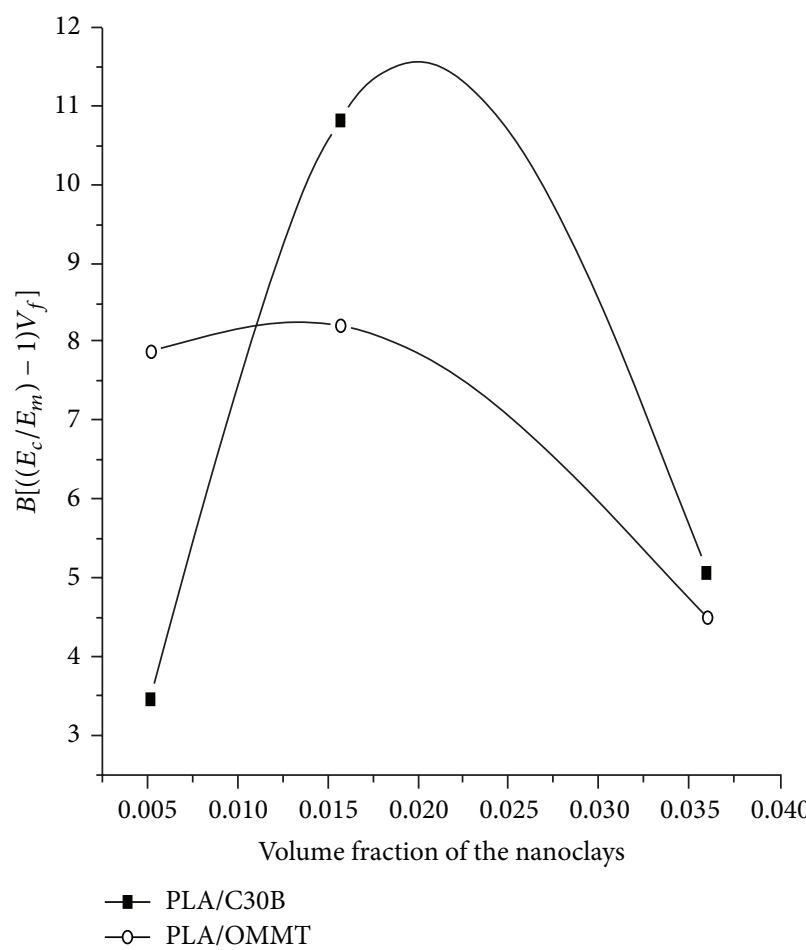

(a)

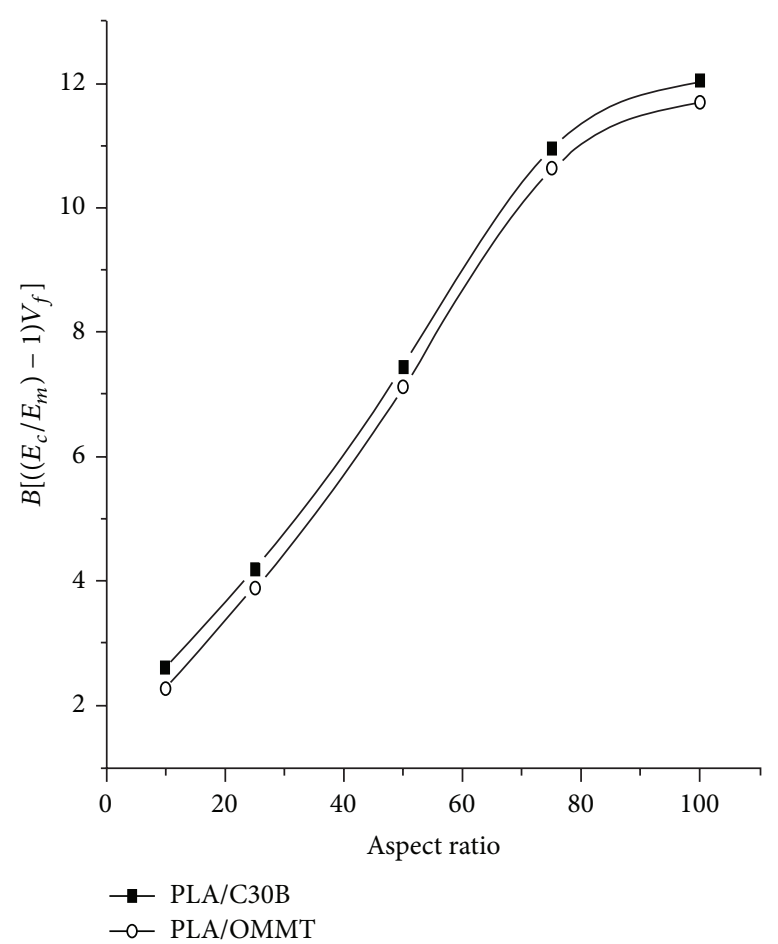

(b)

FIgURE 4: Elasticity of PLA using M-T equation.

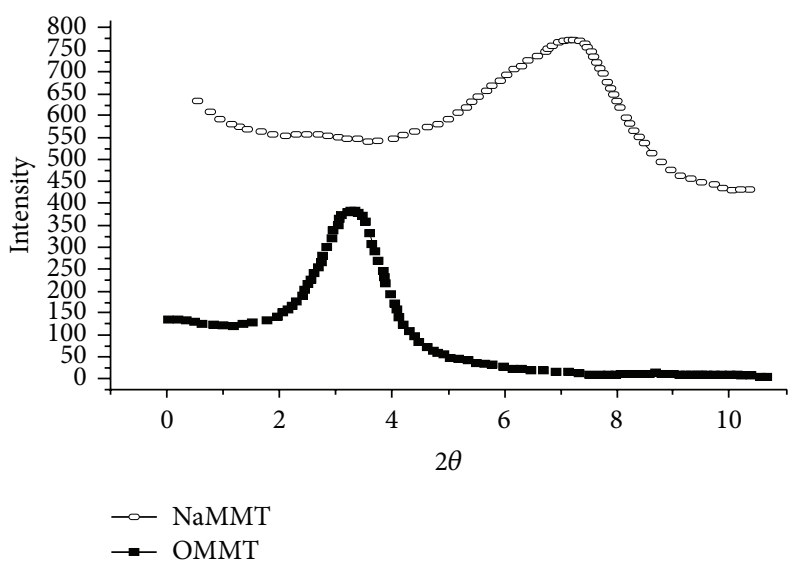

(a)

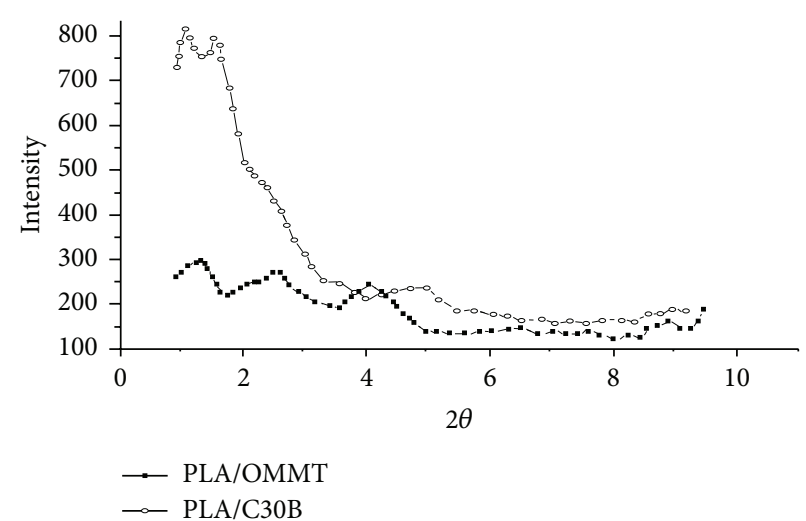

(b)

FIGURE 5: WAXD pattern for nanoclays and nanocomposites.

ratio of the nanoclay as shown in Figure 4(b). Better uniform stress transfer at higher aspect ratio of the filler may be the reason of above trend of elevation of elasticity.

\subsection{Wide Angle X-Ray Diffraction Spectroscopy}

5.5.1. WAXD Analysis of Natural Montmorillonite and $O M M T$. Interstitial spacing in the natural montmorillonite is expected to be expanded by HTAB modification. This is because the penetrated organic tail of HTAB in between the silicate layers can force the successive silicate layers to move apart. This phenomenon was confirmed through WAXD analysis according to the increase in basal spacing of montmorillonite upon HTAB modification. Figure 5(a) shows a comparative account of WAXD patterns of montmorillonite and OMMT, respectively. It is evident that OMMT shows a $2 \theta$ value of $3.3^{\circ}$ corresponding to a $d$ spacing of $2.66 \mathrm{~nm}$ as compared to natural montmorillonite which has a $2 \theta$ value of $7.2^{\circ}$ with a $d$ spacing of $1.33 \mathrm{~nm}$. This increase in the $d$ spacing confirms effective incorporation of HTAB chains on the natural montmorillonite by replacing $\mathrm{Na}^{+}$ion through cation exchange reaction. 
TABLE 2: WAXD results of pristine nanoclays and that in nanocomposites.

\begin{tabular}{|c|c|c|c|c|c|c|}
\hline Sample & 2 Theta (degree) & $d$ spacing $(\mathrm{nm})$ & $2 \theta^{\circ}$ in the nanocomposite & $d$ spacing $(\mathrm{nm})$ in the nanocomposite & $D(\mathrm{~nm})$ & $N=D / d_{001}$ \\
\hline NaMMT & 7.2 & 1.33 & - & - & - & - \\
\hline $\mathrm{C} 30 \mathrm{~B}$ & 4.78 & 1.85 & 1.2 & 5.3 & 35.5 & 4 \\
\hline OMMT & 3.3 & 2.66 & 1.1 & 5.5 & 44.1 & 2 \\
\hline
\end{tabular}

5.5.2. WAXD Analysis of PLA Nanocomposites. The WAXD patterns of the PLA nanocomposites of C30B and OMMT with 3 weight \% loading are displayed in Figure 5(b). In case of PLA/C30B nanocomposite, multiple peaks were observed at low-angle range which confirms the intercalation of silicate layers of $\mathrm{C} 30 \mathrm{~B}$ within the PLA matrix after melt mixing. It is observable that there is a shifting of the diffraction peak of $\mathrm{C} 30 \mathrm{~B}$ to lower angle at $2 \theta=1.2^{\circ}(d$-spacing $\approx 5.3 \mathrm{~nm})$ in $\mathrm{PLA} / \mathrm{C} 30 \mathrm{~B}$ nanocomposite from $2 \theta=4.78^{\circ}(d$-spacing $\approx$ $1.85 \mathrm{~nm}$ ) of pristine $\mathrm{C} 30 \mathrm{~B}$. This indicates that the layer spacing of $\mathrm{C} 30 \mathrm{~B}$ was increased considerably, but its ordered structure was not disrupted after melt mixing. Another small peak is also observed in case of PLA/C30B due to the second registry of MMT clay. The intercalated pattern in PLA/C30B is primarily due to the hydrophilic nature of $\mathrm{C} 30 \mathrm{~B}$ clay and the formation of hydrogen-bond between the carbonyl group in the main chain of PLA molecules and the hydroxyl group in the organic modifier of C30B.

On other hand, WAXD pattern of OMMT within PLA/OMMT nanocomposite has showed a number of peaks with similar level of intensity counts, ranging from 2 to $5.4 \mathrm{~nm}$. This indicates that the stacked layers of OMMT have been well intercalated/exfoliated by the polymer chains. Even though the WAXD pattern does not show a specific high intense diffraction peak, the (001) and its higher order diffractions, for example, (002) and (003), some weak crests have been identified at 1.180, 1.380, and 2.260. The corresponding increased basal spacing in the nanocomposite in comparison with the $d$ spacing of OMMT has been recorded at $5.5 \mathrm{~nm}$, $5.3 \mathrm{~nm}$, and $4.41 \mathrm{~nm}$, respectively.

Width of the WAXD peak, $\beta$ (measured by the full-width at half maximum), is inversely proportional to the coherence length of the scattering entities and therefore reflects the coherence order of the silicate layers. This can be calculated from Scherrer equation [14] as follows:

$$
D=\frac{k \lambda}{\beta \cos \theta},
$$

where $k$ is a constant, generally equal to $0.9, \lambda$ is the $\mathrm{X}$-ray wavelength $(=0.154 \mathrm{~nm}), \beta$ is the width of WAXD peak in radian unit of full width at half maximum, and $\theta$ is the WAXD peak position. As the nanocomposite shows intercalated peaks, the coherency of the nanoclays may be significantly decreased after the melt mixing. This can be studied in more detail by calculating the number of stacked individual silicate layers in the nanocomposites, by taking the ratio of $D$ and $d(001)$, and the data corresponding to this are displayed in Table 2. As observed from the test results reported in the table, the number of clay layers per stacks comes in a range of 35-40 and 4-6, respectively, for $d$ and $D / d(001)$. Vaia et al. $[15,16]$ reported key features of the morphology of intercalated PP/clay nanocomposites using WAXD and TEM. According to them, in case of intercalated and exfoliated/intercalated systems, the particle separation is about $20-50 \mathrm{~nm}$, and this is of the same order of crystal lamellae thickness. On the other hand, Lewitus demonstrated that in an exfoliated/intercalated system of PLA nanocomposites, a single organoclay comprises of $\sim 4$ layers and an average interlayer spacing of $d(001) \sim 2.4 \mathrm{~nm}$ [17].

5.5.3. Transmission Electron Microscopy (TEM). The internal structure of the PLA nanocomposites in the nanometre scale has been investigated from the TEM micrographs. Figures 6(a) and 6(b) show the TEM micrographs of the PLA/C30B and PLA/OMMT, respectively. The dark entities indicate cross section of intercalated or stacked clay layers, which have and an original thickness of around $1 \mathrm{~nm}$, average length of $70-100 \mathrm{~nm}$, and interlayer distance of $100-120 \mathrm{~nm}$. The stacked silicate layers are due to clustering or agglomeration. The bright fields in the TEM micrograph represent the matrix. The nanocomposites show both intercalated and exfoliated regions. OMMT shows better exfoliation or dispersion of clay as compared to C30B within the PLA matrix. Further, few regions showing flocculated as well as intercalated clay galleries were noticed in case of PLA/C30B nanocomposites.

5.6. Dynamic Mechanical Analysis of PLA and Its Nanocomposites. Figures $7(\mathrm{a})$ and $7(\mathrm{~b})$ represent the storage modulus $\left(E^{\prime}\right)$ and $\tan \delta$ of V-PLA and its nanocomposites prepared from $\mathrm{C} 30 \mathrm{~B}$ and OMMT with $3 \mathrm{wt} \%$ loading, as a function of temperature. As evident from the figures, three different regions could be identified; the glassy state (below $60^{\circ} \mathrm{C}$ ), the glass transition (approximately $60-80^{\circ} \mathrm{C}$ ), and the rubbery plateau (approximately between $80-90^{\circ} \mathrm{C}$ ). V-PLA exhibited a glass transition of $73^{\circ} \mathrm{C}$, obtained from the $\tan \delta$ curve. Beyond this transition, the virgin matrix become soft which is evident from the reduction in $E^{\prime}$ by more than 1 order of magnitude. Finally, at $80-90^{\circ} \mathrm{C}$ in the rubbery region, the matrix polymer became extremely soft.

Further, it is observed that, the presence of organoclays had a strong influence on the viscoelastic response of the resulting nanocomposites in the entire investigated range of temperature. In the glassy region, storage modulus $E^{\prime}$ (Figure 7(a)), increased significantly with the incorporation of organically modified nanoclays which indicates the reinforcing effect imparted by the nanosilicate layers. The nanocomposite prepared using C30B nanoclay exhibited higher magnitude of $E^{\prime}$ as compared with the virgin matrix. This behaviour indicates strong inter/intramolecular hydrogen bonded network between the $\mathrm{OH}$ groups of methyl tallow 


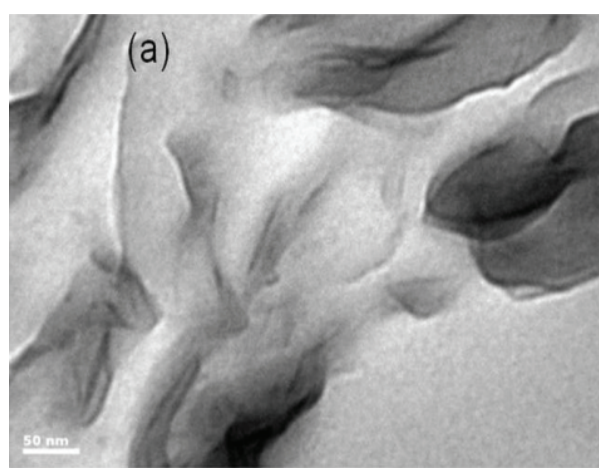

(a)

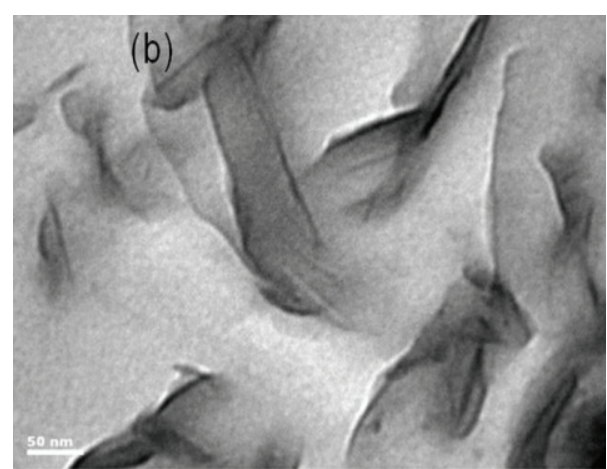

(b)

Figure 6: TEM of nanocomposites.

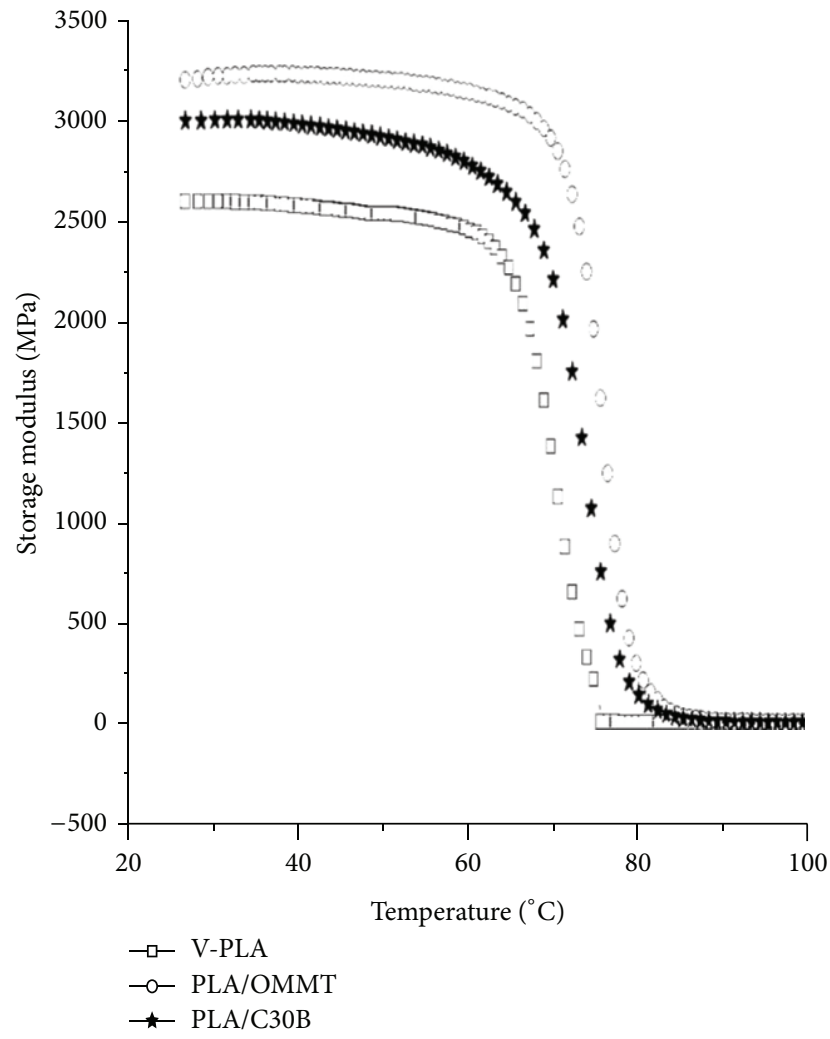

(a)

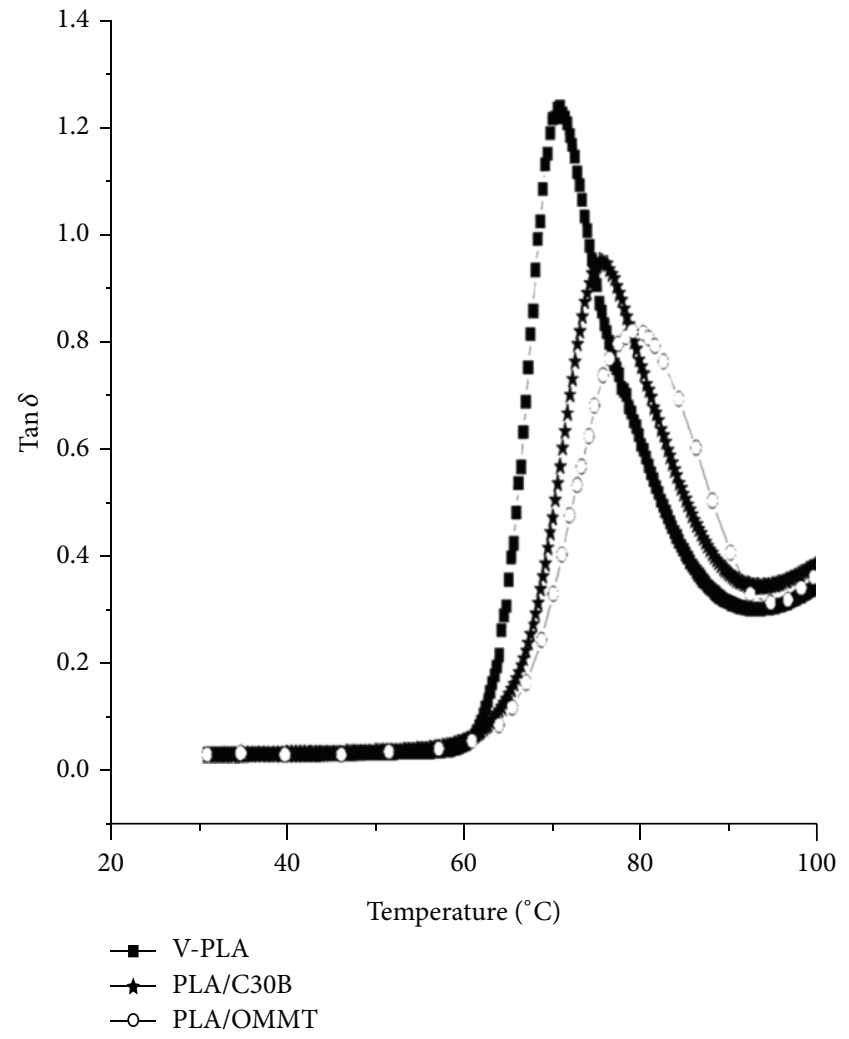

(b)

FIgURE 7: DMA diagrams of PLA and its nanocomposites.

bis-hydroxyethyl intercalant of $\mathrm{C} 30 \mathrm{~B}$ and the $\mathrm{C}=\mathrm{O}$ group of PLA matrix.

Near the glass transition region of PLA, there was a sudden drop in the matrix modulus. However, with the addition of nanoclays, the drop in modulus is compensated with the presence of fillers, due to the segmental immobilization of matrix chains leading to an increase in $E^{\prime}$ and decrease in $\tan \delta$ intensity (Figure 7(b)). Further, it is also noticed that the $T_{g}$ of PLA increased to $81.53^{\circ} \mathrm{C}$ in case of PLA/C30B nanocomposite. This phenomenon is attributed to improved compatibility of the nanoclay with the bulk PLA matrix. PLA/ OMMT based nanocomposite system displayed $T_{g}$ at $83.21^{\circ} \mathrm{C}$ which is marginally less than PLA/C30B probably due to the plasticizing effect of the clay; the cay has showed better impact and elongation characteristics in the static mechanical analysis.

In the rubbery region, an important reinforcing effect was observed due to the presence of the nanoclays. As evident from the $\tan \delta$ curves, a maximum in the relaxation beyond $79^{\circ} \mathrm{C}$ was observed in the filled systems. V-PLA revealed a relaxation maximum around $75^{\circ} \mathrm{C}$ which subsequently increased in both nanocomposites. The nanocomposites prepared using OMMT and C30B nanoclay with 3 weight \% filler loading showed an optimum increase in the relaxation 

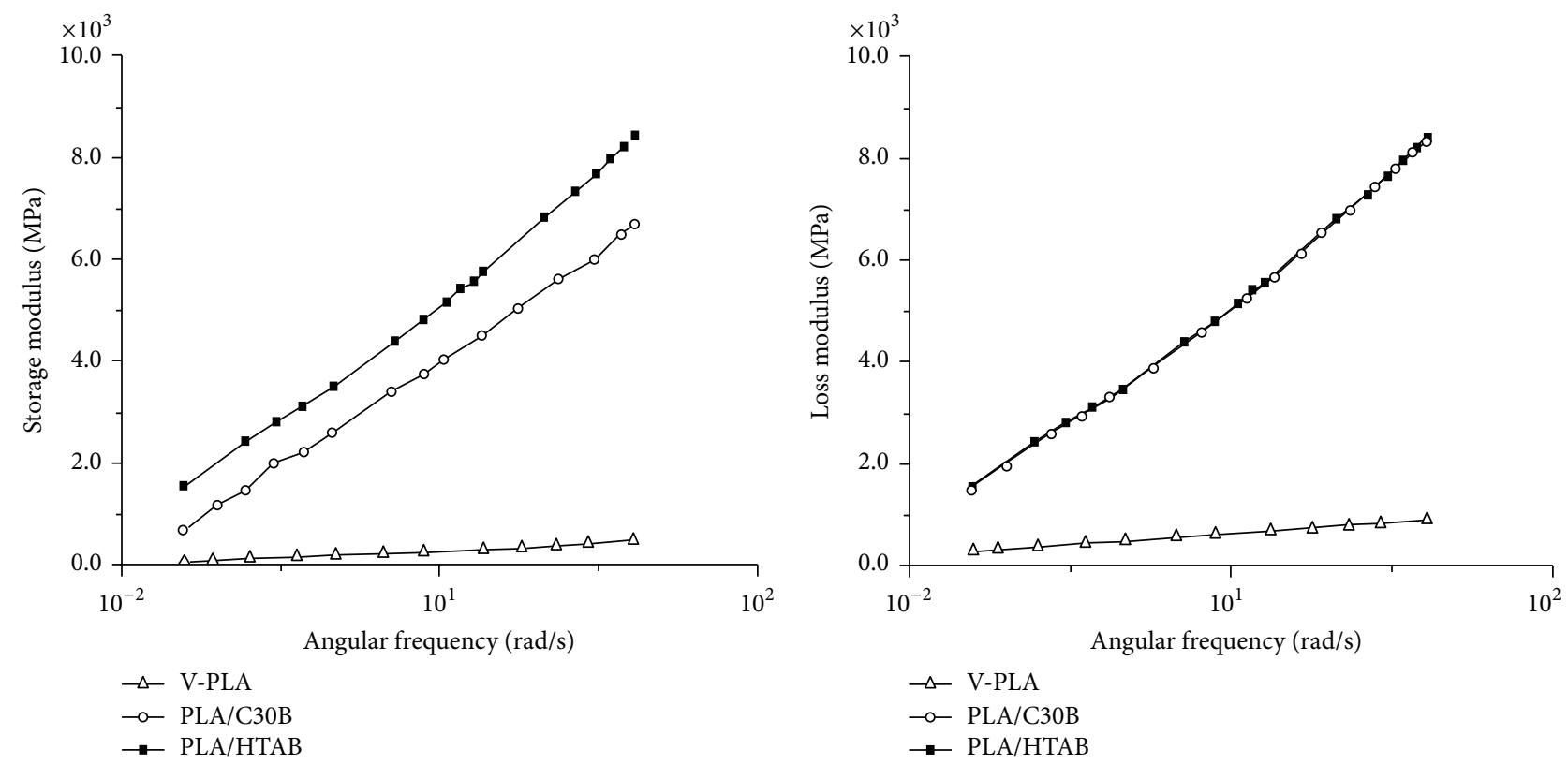

(a)

(b)

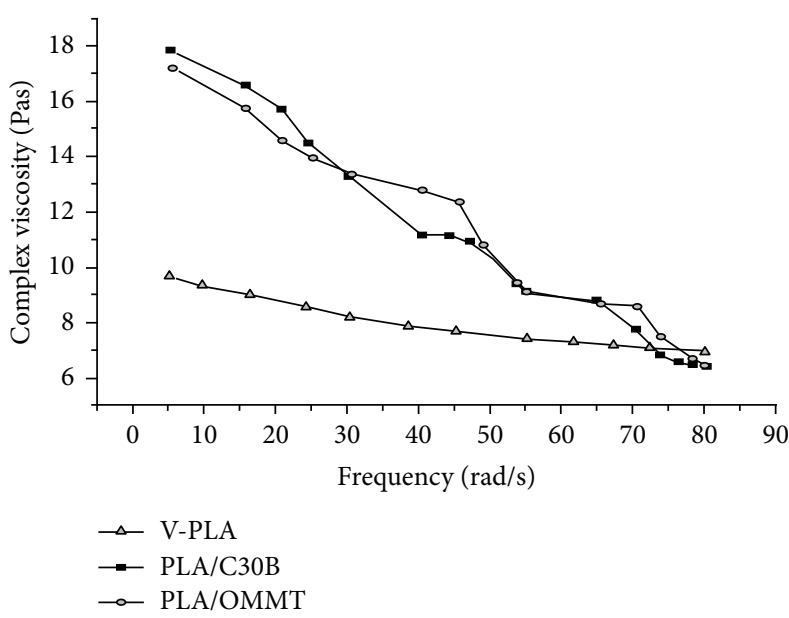

(c)

FIGURE 8: Rheological diagrams of PLA and its nanocomposites.

maximum to $80-82^{\circ} \mathrm{C}$ thus indicating improved dispersion characteristics of the organically modified clays due to the larger surface area between the reinforcement phase and the polymer matrix.

5.7. Rheological Properties of PLA and Its Nanocomposites. The variation of dynamic storage modulus $\left(G^{\prime}\right)$, dynamic loss modulus, and complex viscosity of virgin PLA and its optimised nanocomposites is depicted in Figures 8(a), 8(b), and 8(c), respectively. As observed from Figure 8, the nanocomposites exhibited an increase in the $G^{\prime}$ and $G^{\prime \prime}$ of PLA, within the experimentally investigated frequency range. This indicates slow transition from the classical liquid like characteristics to pseudosolid nature. Even though, the transition nature has observed the whole analysis region $G^{\prime}<G^{\prime \prime}$, indicating the nanocomposites also does not come out of classical liquid-like behaviour of the molten V-PLA. Higher $G^{\prime}$ and $G^{\prime \prime}$ for both the nanocomposites compared with the virgin matrix reveals the reinforcing effect of nanoclays. In case of the matrix polymer, the $G^{\prime}$ and $G^{\prime \prime}$ varied from 200 to $550 \mathrm{~Pa}$ and 400 to $850 \mathrm{~Pa}$, respectively, from low to high frequency regions. However, the nanocomposites showed higher magnitude of $G^{\prime}$ and $G^{\prime \prime}$ from 900 to $7000 \mathrm{~Pa}$ and 1500 to $8500 \mathrm{~Pa}$ for the nanocomposites. This behaviour is primarily due to the increase in the rigidity of network structure in the matrix with the incorporation of nanoclay.

As discussed in the earlier sections in DMA studies, the crystalline domain of the PLA has been well improved due to the nucleating effect of the intercalated/exfoliated nanoclays. Similar facts of increased stiffness have been corroborated with the increased rheological properties $\left(G^{\prime}\right.$ and $\left.G^{\prime \prime}\right)$ of PLA 
in the nanocomposites. Ray and coworkers described similar behaviour of increment in melt state rheological properties of polyester nanocomposites. They found like other properties, rheological properties of nanocomposites are also directly related to the degree of dispersion of the silicate layers in the matrix polymer and level of interfacial interactions between the layered silicate surface and polymer chains [18].

In accordance with the time temperature superposition (TTS) concept, at high frequency region $\left(a_{T} \omega>10\right)$ and low frequency region $\left(a_{T} \omega<10\right)$ both the $G^{\prime}$ and $G^{\prime \prime}$ displayed similar characteristics of $G^{\prime}<G^{\prime \prime}$, and even though the cross over point could not be located within the experimental range, the difference in $G^{\prime}$ and $G^{\prime \prime}$ considerably decreased with the increase in frequency. This indicates that the frequency independent liquid-like $\left(G^{\prime} \alpha \omega^{2}\right.$ and $\left.G^{\prime \prime} \alpha \omega\right)$ behavior slowly transmitted to "pseudo-solid like" behavior in case of both V-PLA and the nanocomposites. Intensity of this phenomenon was higher in case of nanocomposites than that of V-PLA. This may be due to the increased melt strength by the reinforcing effect of the nanoclays exfoliate/intercalated within the PLA matrix. Also the slopes of $G^{\prime}$ and $G^{\prime \prime}$ in the terminal region of the master curves of PLA matrix were 1.43 and 0.87 , respectively. On other hand, the slopes of $G^{\prime}$ and $G^{\prime \prime}$ for PLA/C30B nanocomposites were observed at 0.62 and 0.55 . This further confirms transition from "liquid like" to "pseudo-solid like" behaviour at lower to higher angular frequency for V-PLA as well as nanocomposites.

The variation of complex viscosity $\left(\eta^{*}\right)$ as a function of angular frequency $(\omega)$ of V-PLA and its nanocomposites with 3 weight $\%$ filler loading is depicted in Figure 8(c). It is evident that both the virgin polymer as well as the nanocomposites exhibited transition to non-Newtonian pseudoplastic behaviour within the studied deformation region of $0.01 \mathrm{rad} / \mathrm{sec}$ to $100 \mathrm{rad} / \mathrm{sec}$. As observed from the figures, the viscosity decreases consistently with the increase in angular frequency, thus revealing typical characteristics of a completely frequency dependant nature. Both PLA and the nanocomposites exhibited a shear thinning effect unlike other thermoplastic matrices [19]. But the effect is more pronounced in the case of nanocomposite as compared with that of the virgin matrix. According to Pluta et al., the real part of the complex viscosity is an energy dissipation term similar to the imaginary part of the complex modulus [20].

The magnitude of $\eta^{*}$ in case of V-PLA matrix was observed in the range of 10 to $7 \mathrm{~Pa}$ s which increased considerably in the nanocomposites from 20 to $7 \mathrm{~Pa}$ s. This increase in the $\eta^{*}$ over the entire experimentally investigated frequency region reflects the reinforcement effect of the nanoclay within the molten polymer matrix. Iannace and Nicolais reported such kind of improvement in $\eta^{*}$ of PLA nanocomposite than that of the virgin matrix [21]. According to the author, the reinforcing effect results from the interaction between the components due to hydrogen bonding of carbonyl groups of the PLA matrix and hydroxylated organic "surfactant" ends of the nanoclay that opposes the applied external shear effectively.

According to Ray and Okamoto [19], the increment in complex viscosity of the PLA nanocomposite was observed in comparison with the virgin matrix. The author attributed this behaviour due to the presence of stacks of intercalated/exfoliated silicate layers that are randomly oriented in the polymer matrix, forming a 3D network structure. These intercalated/exfoliated layers have only translational motion. A large amplitude oscillatory shear is able to orient these structures thereby increasing the coefficient of viscosity. Another explanation for such kind of behaviour of improved $\eta^{*}$ is probably due to the phenomenon of physical jamming of the dispersed silicate layers owing to their highly anisotropic nature. On the basis of intercalated/exfoliated mesoscopic pattern observed for the nanocomposites in the present investigation, the individual silicate layers are incapable of free rotation and when subjected to shear, they are prevented from a completely relaxed state. This incomplete relaxation due to the physical jamming or percolation of the nanoscopic fillers leads to the pseudosolid like behaviour for nanocomposites with intercalated/exfoliated structures.

\section{Conclusion}

Exfoliated/intercalated PLA nanocomposites based on two different organomodified natural montmorillonites have been successfully prepared by melt mixing method. WAXD and TEM studies confirmed exfoliated/intercalated pattern of both the nanoclays within the PLA matrix. Improved mechanical properties as tensile and impact strength point the reinforcing effect of clay layers within PLA. High level of exfoliated OMMT within the matrix tends to enhance the mechanical properties of corresponding nanocomposite, whereas polar hydroxylated modifier end of C30B has compatibilized the PLA/C30B nanocomposite. Similar with the static mechanical analysis, dynamic mechanical analysis also revealed reinforcing effect of both the nanoclays with 3 weight \% loading. Formation of delayed rubbery plateau for nanocomposites (in the range of $81-83^{\circ} \mathrm{C}$ ) in comparison with V-PLA $\left(\approx 72^{\circ} \mathrm{C}\right)$ was observed during DMA analysis. On the other hand, the increased processability has been justified by the observed intense transition from "liquid like" to "pseudoplastic" nature in case of nanocomposites than V-PLA during rheological analysis. Even though both the nanocomposites showed properties improvement, PLA/OMMT showed superior characteristics than that of PLA/C30B in terms of mechanical and rheological properties.

\section{References}

[1] S. S. Ray, P. Maiti, M. Okamoto, K. Yamada, and K. Ueda, "New polylactide/layered silicate nanocomposites. 1. Preparation, characterization, and properties," Macromolecules, vol. 35, no. 8, pp. 3104-3110, 2002.

[2] J. Y. Nam, S. S. Ray, and M. Okamoto, "Crystallization behavior and morphology of biodegradable polylactide/layered silicate nanocomposite," Macromolecules, vol. 36, no. 19, pp. 7126-7131, 2003.

[3] K. Ueda, S. S. Ray, K. Yamada, and M. Okamoto, "New polylactide-layered silicate nanocomposites. 2. Concurrent improvements of material properties, biodegradability and melt rheology," Polymer, vol. 44, no. 3, pp. 857-866, 2002. 
[4] S. S. Ray, K. Yamada, M. Okamoto, A. Ogami, and K. Ueda, "New polylactide/layered silicate nanocomposites. 3. Highperformance biodegradable materials," Chemistry of Materials, vol. 15, no. 7, pp. 1456-1465, 2003.

[5] R. Krishnamoorti, R. A. Vaia, and E. P. Giannelis, "Structure and dynamics of polymer-layered silicate nanocomposites," Chemistry of Materials, vol. 8, no. 8, pp. 1728-1734, 1996.

[6] S. S. Ray, K. Yamada, M. Okamoto, and K. Ueda, "Biodegradable polylactide/montmorillonite nanocomposites," Journal of Nanoscience and Nanotechnology, vol. 3, no. 6, pp. 503-510, 2003.

[7] O. Yoshida and M. Okamoto, "Direct melt intercalation of polylactide chains into nano-galleries: interlayer expansion and nano-composite structure," Macromolecular Rapid Communications, vol. 27, no. 10, pp. 751-757, 2006.

[8] S. S. Ray, K. Yamada, M. Okamoto, A. Ogami, and K. Ueda, "New polylactide/layered silicate nanocomposites, 4. Structure, properties and biodegradability," Composite Interfaces, vol. 10, no. 4-5, pp. 435-450, 2003.

[9] A. Bouaziz, F. Zaïri, M. Naït-Abdelaziz, J. M. Gloaguen, and J. M. Lefebvre, "Micromechanical modelling and experimental investigation of random discontinuous glass fiber polymermatrix composites," Composites Science and Technology, vol. 67, no. 15-16, pp. 3278-3285, 2007.

[10] K. C. Shive and Y. T. Guang, "Micromechanical modeling of material damping in discontinuous fiber three-phase polymer composites," Composites Engineering, vol. 1, no. 1, pp. 49-60, 1991.

[11] G. Kalaprasad, K. Joseph, S. Thomas, and C. Pavithran, “Theoretical modelling of tensile properties of short sisal fibrereinforced low-density polyethylene composites," Journal of Materials Science, vol. 32, no. 16, pp. 4261-4267, 1997.

[12] G. Lin, X. Zhang, L. Liu, J. Zhang, Q. Chen, and L. Zhang, "Study on microstructure and mechanical properties relationship of short fibers/rubber foam composites," European Polymer Journal, vol. 40, no. 8, pp. 1733-1742, 2004.

[13] G. Kalaprasad, K. Joseph, S. Thomas, and C. Pavithran, “Theoretical modelling of tensile properties of short sisal fibrereinforced low-density polyethylene composites," Journal of Materials Science, vol. 32, no. 16, pp. 4261-4267, 1997.

[14] J. R. Fried, Polymer Science and Technology, Prentice-Hall, Delhi, India, 2nd edition, 2005.

[15] R. A. Vaia, R. K. Teukolsky, and E. P. Giannelis, "Interlayer structure and molecular environment of alkylammonium layered silicates," Chemistry of Materials, vol. 6, no. 7, pp. 1017-1022, 1994.

[16] D. Lewitus, S. McCarthy, A. Ophir, and S. Kenig, "The effect of nanoclays on the properties of PLLA-modified polymers Part 1: mechanical and thermal properties," Journal of Polymers and the Environment, vol. 14, no. 2, pp. 171-177, 2006.

[17] M.-A. Paul, C. Delcourt, M. Alexandre, P. Degée, F. Monteverde, and P. Dubois, "Polylactide/montmorillonite nanocomposites: study of the hydrolytic degradation," Polymer Degradation and Stability, vol. 87, no. 3, pp. 535-542, 2005.

[18] S. S. Ray, K. Yamada, M. Okamoto, Y. Fujimoto, A. Ogami, and K. Ueda, "New polylactide/layered silicate nanocomposites. 5. Designing of materials with desired properties," Polymer, vol. 44, no. 21, pp. 6633-6646, 2003.

[19] S. S. Ray and M. Okamoto, "New polylactide/layered silicate nanocomposites, 6a melt rheology and foam processing," Macromolecular Materials and Engineering, vol. 288, no. 12, pp. 936-944, 2003.
[20] M. Pluta, A. Galeski, M. Alexandre, M.-A. Paul, and P. Dubois, "Polylactide/montmorillonite nanocomposites and microcomposites prepared by melt blending: structure and some physical properties," Journal of Applied Polymer Science, vol. 86, no. 6, pp. 1497-1506, 2002.

[21] S. Iannace and L. Nicolais, "Isothermal crystallization and chain mobility of poly(L-lactide)," Journal of Applied Polymer Science, vol. 64, no. 5, pp. 911-919, 1997. 

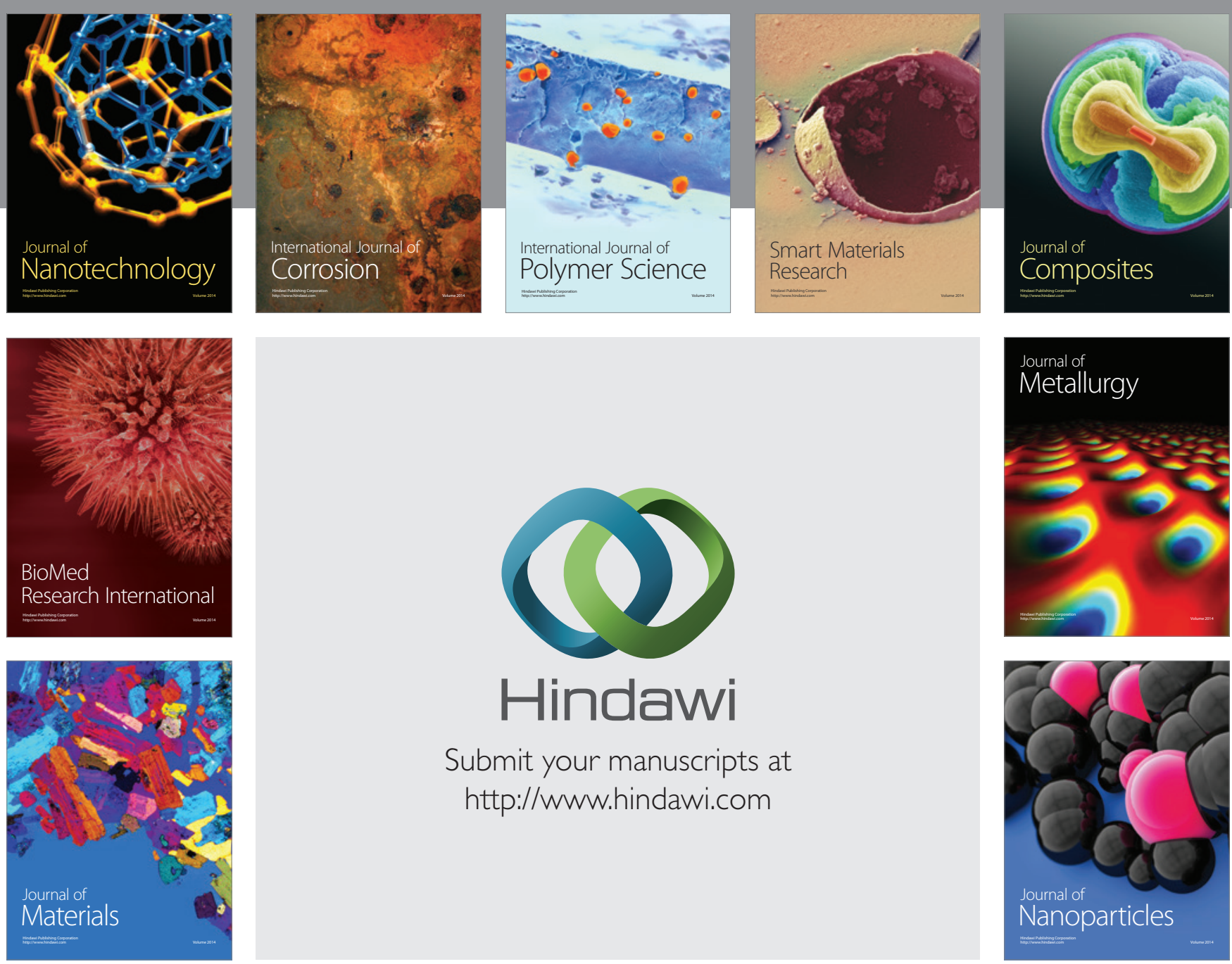

Submit your manuscripts at http://www.hindawi.com
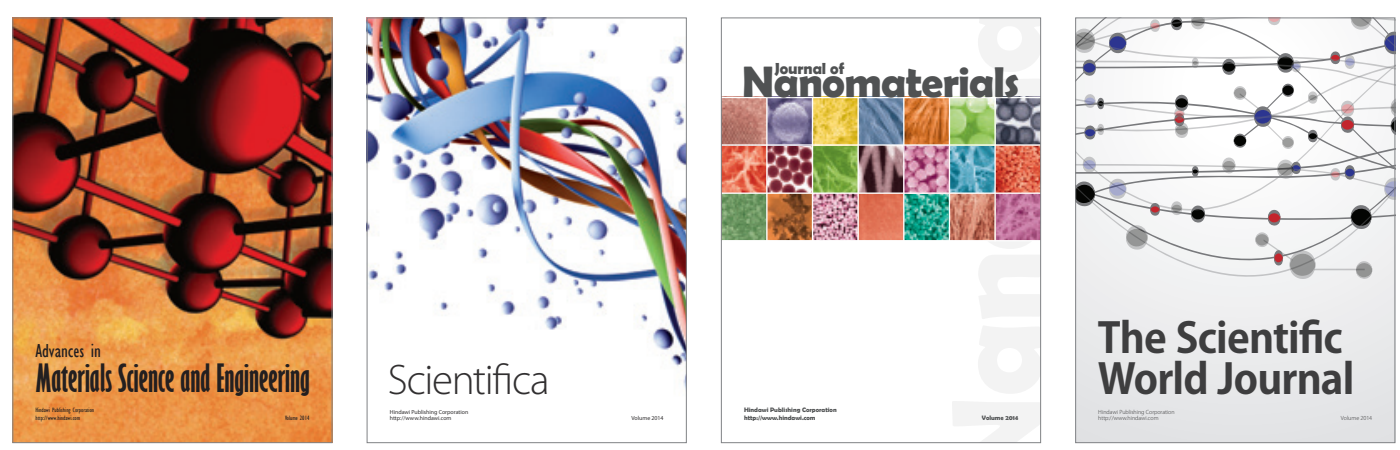

\section{The Scientific World Journal}
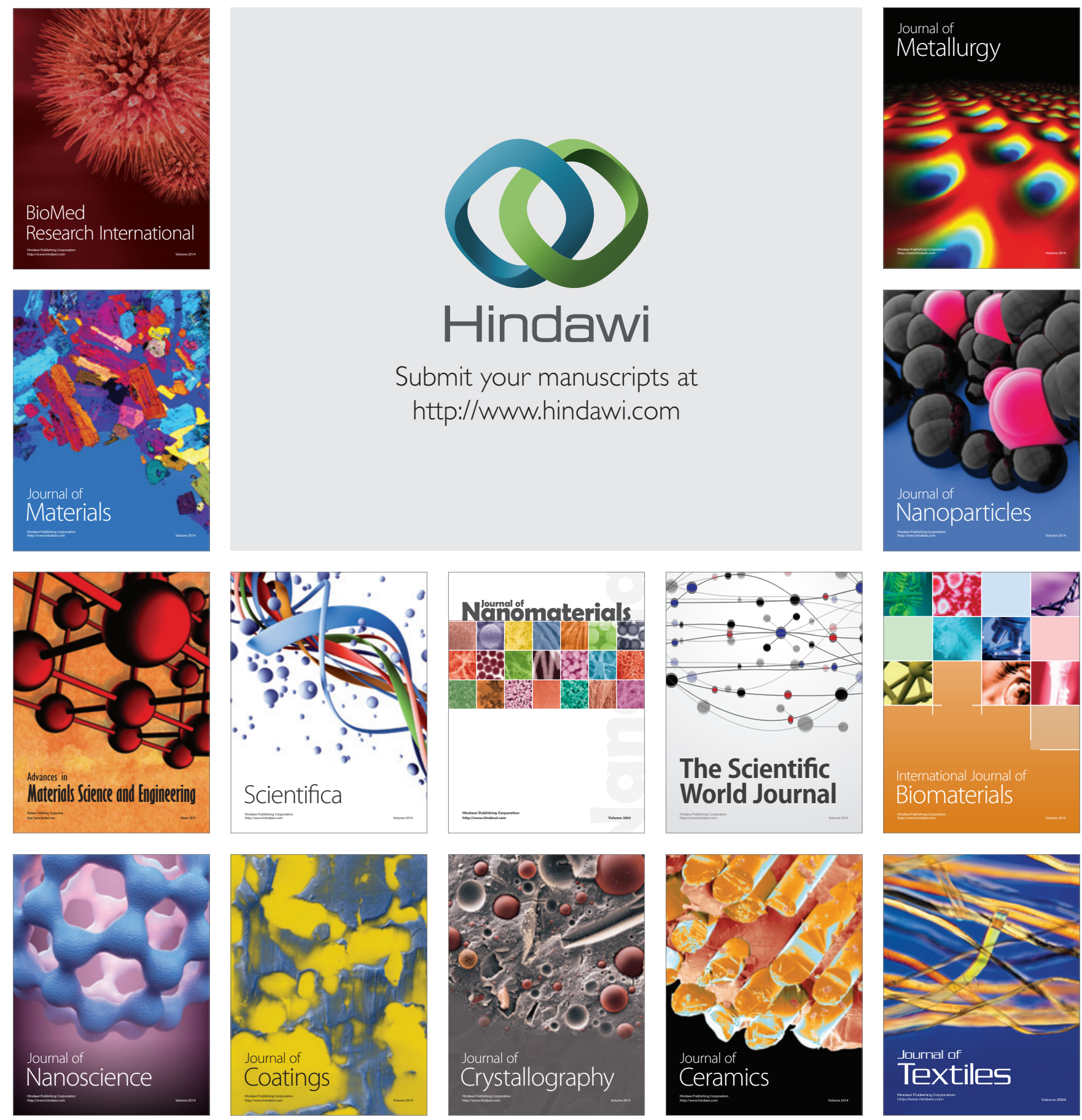